\title{
A Semianalytical Model for Multiple-Fractured Horizontal Wells with SRV in Tight Oil Reservoirs
}

\author{
Jiahang Wang, ${ }^{1,2,3}$ Xiaodong Wang, ${ }^{1,2}$ and Wenxiu Dong ${ }^{1,3}$ \\ ${ }^{1}$ School of Energy Resource, China University of Geosciences (Beijing), Beijing 100083, China \\ ${ }^{2}$ Key Laboratory of Strategy Evaluation for Shale Gas, Ministry of Land and Resources, Beijing 100083, China \\ ${ }^{3}$ Beijing Key Laboratory of Unconventional Natural Gas Geological Evaluation and Development Engineering, Beijing 100083, China \\ Correspondence should be addressed to Xiaodong Wang; wangxd_cugb@126.com
}

Received 20 June 2017; Revised 4 September 2017; Accepted 17 October 2017; Published 29 November 2017

Academic Editor: Ebrahim Fathi

Copyright (C) 2017 Jiahang Wang et al. This is an open access article distributed under the Creative Commons Attribution License, which permits unrestricted use, distribution, and reproduction in any medium, provided the original work is properly cited.

\begin{abstract}
The paper developed a new semianalytical model for multiple-fractured horizontal wells (MFHWs) with stimulated reservoir volume (SRV) in tight oil reservoirs by combining source function theory with boundary element idea. The model is first validated by both analytical and numerical model. Then new type curves are established. Finally, the effects of SRV shape, SRV size, SRV permeability, and parameters of hydraulic fractures are discussed. Results show that SRV has great influence on the pressure response of MFHWs; the parameters of fractures, such as fracture distribution, length, and conductivity, also can affect the transient pressure of MFHWs. One novelty of this model is to consider the nonlinear flow around hydraulic fracture tips. The other novelty is the ability to model the shape of the SRV, production behavior of different fractures, and interfaces. Compared to numerical and analytic methods, this model can not only reduce extensive computing processing but also show high accuracy.
\end{abstract}

\section{Introduction}

With the increasing demand of energy market and great progress of hydraulic fracturing technology, the exploration of unconventional resources such as tight oil, tight gas, and shale gas becomes more and more important [1-5]. Compared to the conventional hydraulic fracturing and horizontal wells, multiple-fractured horizontal wells technology can form a certain enhanced region with induced fractures near the hydraulic fractures, which changes the flow pattern, reduces the flow resistance, and improves the production of a single well $[6,7]$. However, establishing a dynamic analysis model of MFHWs with stimulated reservoir volume (SRV) under such complex geological conditions is difficult. One of the difficulties is that it is hard to describe the degree and shape of the SRV accurately. The other one is that it is difficult to deal with the coupling between the enhanced region and unstimulated region.

Many scholars have done a lot of researches on SRV characterization and its effects on well performance. Various analytical and detailed numerical models have been proposed. Among these models, multilinear models are the most widely used. Ozkan et al. $[8,9]$ utilized a trilinear flow model to investigate the MFHWs performance in unconventional reservoirs. Brown et al. [10] proposed an analytical trilinear flow model to describe the pressure distribution for a system, where the enhanced region occupies entire spaces near the fractures. Stalgorova and Mattar [11] improved the trilinear flow model by simplifying the SRV into an enhanced region with limited width. Five regions are defined to simulate the SRV and all the flow in these regions is linear. Guo et al. [12] presented an analytical model for the multistage fractured shale reservoir, considering heterogeneity, typical seepage characters, and fluids flow from upper/lower reservoir. The model is similar to five-region-flow model but subdivides the reservoir into seven parts.

Many other researchers try to replace the shape of SRV with other methods. Ketineni and Ertekin [13] generated a composite natural fractured system solution in elliptical flow geometry. The enhanced region is simulated by the elliptical flow model. Like other elliptical studies, the reservoir pressure with a series of Mathieu functions is obtained. The model is complex and cannot describe the geometry of the main fracture. Zhao et al. [14] simplified the model 


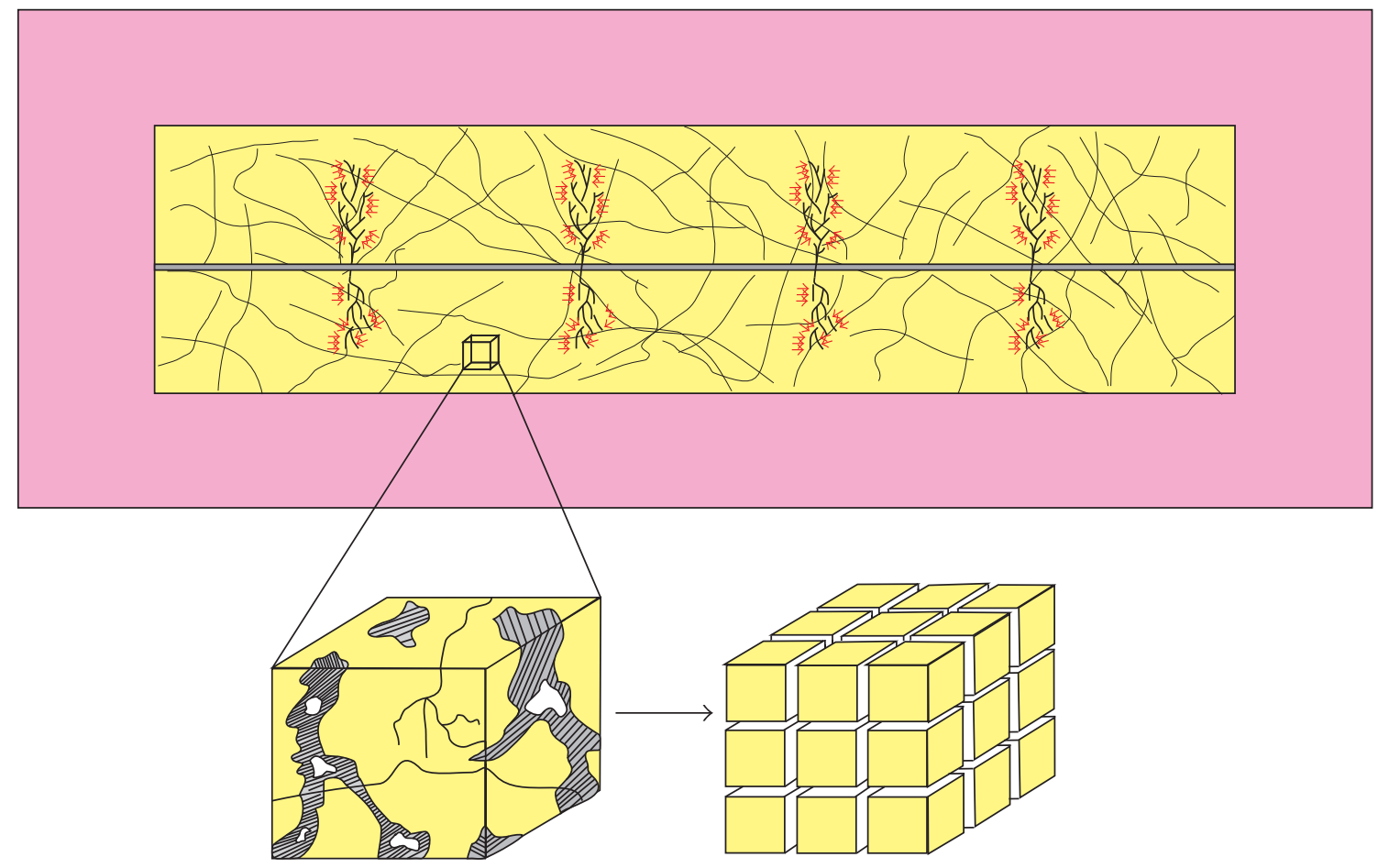

FIGURE 1: Schematic of MFHW with SRV in a rectangular reservoir.

by describing the shape of enhanced region as circle. Ozcan et al. [15] and Wang [16] combined linear flow with fractal theory and provided alternative method to simulate well performance in fractured reservoir. Although the fractal model can well describe the spatial distribution of fractures, it cannot optimize the parameters of hydraulic fracture.

Despite the efforts presented in the literature, all above models are limited by two assumptions. One assumption is that the fluid flow in all regions is linear. In fact, innovative fracturing techniques such as "Simulfrac" and "Zipperfrac" can create an enhanced region with high density network of fractures [17]. The flow in the enhanced region near hydraulic fracture tips may no longer behave like linear flow, but, instead, radial flow. Existing multilinear models become inapplicable. The other deficient assumption is that both the shapes of unstimulated and enhanced region are simplified as circles. In fact, due to the long length of the horizontal wellbore, the shape of enhanced region should be approximately ellipse or rectangle rather than circle.

The object of this paper is to establish a semianalytical model for MFHWs with SRV in tight reservoirs. To overcome the limitations, this study combines the point source/sink theory with boundary element idea to solve the seepage flow. The reservoir is divided into several subsystems. The subsystems in the enhanced region are modeled by WarrenRoot [18] dual-porosity model. The fluid flow near the fracture tips includes both linear flow and radial flow. The transient pressure responses of MFHWs with considering the effect of SRV are investigated and the influence of relevant parameters on type curves is also analyzed.

\section{Methodology}

2.1. Physical Model and Assumptions. The schematic diagram for a MFHW in a tight oil reservoir is shown in Figure 1. Propagation of fractures can create branch patterns [19]. Fracture branching creates a stimulated reservoir volume around each artificial hydraulic fracture, which can be modeled by introducing a region of higher permeability. According to the reservoir physical conditions, the whole reservoir is subdivided into inner and outer regions. The inner region is composed of matrix, natural fractures, and induced fractures, which can be simulated by Warren-Root [18] dual-porosity model. The outer region is an unstimulated homogeneous media which is not influenced by hydraulic fractures. The basic assumptions of the model are as follows:

(1) The MFHW is located in the center of a rectangular tight oil reservoir with impermeable outer boundaries and produces at a constant rate $q . n f$ artificial hydraulic fractures distribute evenly along the horizontal wellbore.

(2) The thickness of reservoir is $h$ and uniform initial pressure is $p_{i}$.

(3) The formation is fully penetrated by the artificial hydraulic fractures.

(4) Isothermal single phase fluid flow is assumed.

(5) The influence of gravity and capillary forces on fluid flow in both regions is ignored.

\subsection{Mathematical Model and Solution}

2.2.1. Mathematical Model. In order to describe the complex flow model stated above accurately, we combine the 


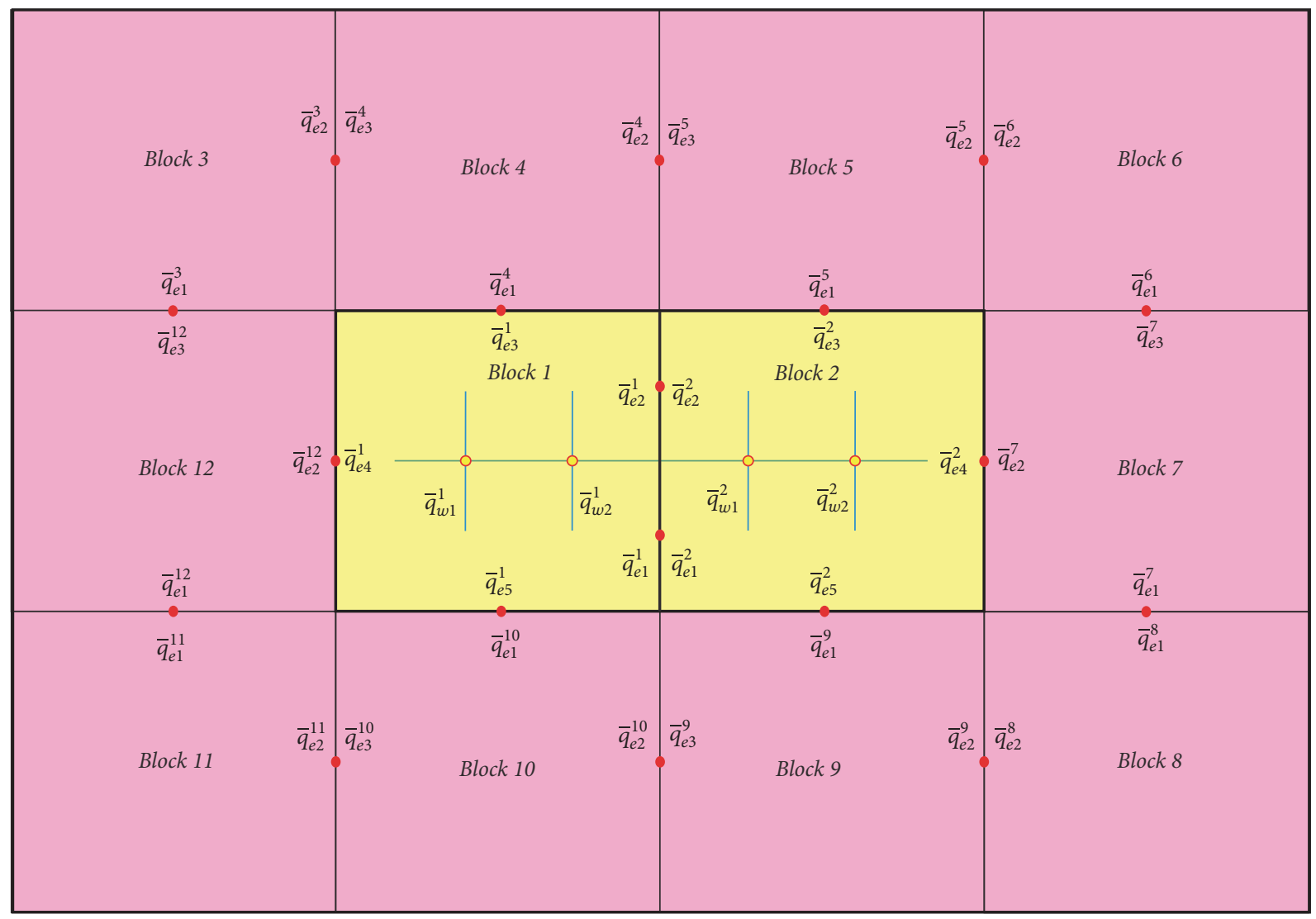

FIGURE 2: The grid model for MFHW with SRV in a rectangular reservoir.

source/sink theory with boundary element idea. The whole reservoir is subdivided into 12 discrete blocks based on the reservoir properties. Due to the fully penetration of the fractures, the issue can be studied in two dimensions (Figure 2). For convenience, the solutions of this model are founded on dimensionless variables. These dimensionless parameters are defined as follows:

$$
\begin{aligned}
p_{j D} & =\frac{\alpha_{p} \lambda_{\text {ref }} h\left(p_{i}-p_{j}\right)}{q B} ; \\
t_{D} & =\frac{\alpha_{t} \eta_{\text {ref }} t}{L_{f}^{2}} ; \\
c_{f i D} & =\frac{k_{f i} w_{f i}}{k_{i} L_{f i}} ; \\
q_{w i D} & =\frac{q_{w i}(t) 2 y_{f i} h}{q B} ; \\
q_{e j D} & =\frac{q_{e j}(t) 2 \delta_{p j} h}{q B}, \quad \delta=x, y, \\
\lambda_{\text {in-out } j} & =\frac{(k / \mu)_{j}}{(k / \mu)_{\text {ref }}} ;
\end{aligned}
$$

$$
\begin{aligned}
\omega_{\text {in-out } j} & =\frac{\left(\phi c_{t}\right)_{j}}{\left(\phi c_{t}\right)_{\text {ref }}} \\
\eta_{j D} & =\frac{\eta_{j}}{\eta_{\text {ref }}}=\frac{\lambda_{\text {in-out } j}}{\omega_{\text {in-out } j}} \\
y_{f i D} & =\frac{y_{f i}}{L_{f}} ; \\
y_{D} & =\frac{y}{L_{f}} ; \\
y_{w i D} & =\frac{y_{w i}}{L_{f}} ; \\
y_{e D j} & =\frac{y_{e j}}{L_{f}} \\
x_{D} & =\frac{x}{L_{f}} ; \\
x_{e j D} & =\frac{x_{e j}}{L_{f}} . \\
x_{w i D} & =\frac{x_{w i}}{L_{f}}
\end{aligned}
$$


The dimensionless pressure of horizontal well is $p_{w D}$. The dimensionless flux and pressure at the center of $i$ th fracture in block $k$ are $\bar{q}_{w D i}^{k}, \bar{p}_{w D i}^{k}, i=1,2, \ldots, n f / 2 ; k=1,2$, respectively. The dimensionless flux and pressure at the center of $j$ th interface segment in block $k$ are $\bar{q}_{e D j}^{k}, \bar{p}_{e D j}^{k}, j=1,2, \ldots, 5$, $k=1,2, \ldots, 12$, respectively.

2.2.2. Solution. When $n+m$ sources/sinks in a reservoir produce simultaneously, the dimensionless pressure drop at any location $\left(x_{D}, y_{D}\right)$ in the reservoir is equal to the sum of the dimensionless pressure drop caused by every single sources/sink [6]. Since the flux of each source/sink is a function of time, according to the Duhamel convolution, the pressure distribution in Laplace transform domain can be expressed as

$$
\Delta \bar{p}_{D}=\left[\sum_{i=1}^{n} \bar{q}_{w D i} \cdot \bar{S}_{w i}\right]+\left[\sum_{j=1}^{m} \bar{q}_{e D j} \cdot \bar{S}_{e j}\right] .
$$

Due to the full penetration of the fractures, both the source functions for hydraulic fractures and interface segments are line source function. $\bar{S}_{\alpha}, \alpha=w D i$ (hydraulic fracture) and $\alpha=e D j$ (interface segment), can be expressed as follows [20]:

$$
\begin{aligned}
\bar{S}_{w D i} & =\frac{\omega_{\text {in-out } i}}{\lambda_{\text {in-out } i}}\left\{\frac{\pi}{y_{e D i}} \widetilde{H}_{y 0}\right. \\
+ & \left.\frac{2}{y_{p i}} \sum_{n=1}^{\infty} \frac{1}{n} \widetilde{H}_{y n} \cos \frac{n \pi y_{w D i}}{y_{e D i}} \cos \frac{n \pi y_{D}}{y_{e D i}} \sin \frac{n \pi y_{p i}}{y_{e D i}}\right\}, \\
\bar{S}_{e D j} & =\frac{\omega_{\text {in-out } j}}{\lambda_{\text {in-out } j}}\left\{\frac{\pi}{\delta_{e D j}} \widetilde{H}_{\delta 0}\right. \\
& \left.+\frac{2}{\delta_{p j}} \sum_{n=1}^{\infty} \frac{1}{n} \widetilde{H}_{\delta n} \cos \frac{n \pi \delta_{w D j}}{\delta_{e D j}} \cos \frac{n \pi \delta_{D}}{\delta_{e D j}} \sin \frac{n \pi \delta_{p j}}{\delta_{e D j}}\right\},
\end{aligned}
$$

where

$$
\begin{aligned}
& \widetilde{H}_{\delta n}= \begin{cases}\frac{\cosh \varepsilon_{\alpha n}\left(y_{e D j}-\left|y_{D} \pm y_{w j D}\right|\right)}{\varepsilon_{\alpha n} \sinh \varepsilon_{\alpha n} y_{e D j}} & \delta=x \\
\frac{\cosh \varepsilon_{\alpha n}\left(x_{e D i}-\left|x_{D} \pm x_{w i D}\right|\right)}{\varepsilon_{\alpha n} \sinh \varepsilon_{\alpha n} x_{e D i}} & \delta=y,\end{cases} \\
& \varepsilon_{\alpha n}= \begin{cases}\sqrt{u_{\delta}+\frac{n^{2} \pi^{2}}{y_{e D i}^{2}}} & \alpha=w D i \\
\sqrt{u_{\delta}+\frac{n^{2} \pi^{2}}{\delta_{e D j}^{2}}} & \alpha=e D j\end{cases}
\end{aligned}
$$

$$
\begin{array}{r}
u_{\delta}= \begin{cases}\frac{u}{\lambda_{\text {in-outi }}} & \delta=y, \alpha=w D i \\
\frac{u}{\lambda_{\text {in-out } j}} & \delta=x, y, \alpha=e D j\end{cases} \\
u=\left\{\begin{array}{l}
s \\
s f(s) ;
\end{array}\right. \\
f(s)=\frac{s \omega_{m-f}\left(1-\omega_{m-f}\right)+\lambda_{m-f}}{s\left(1-\omega_{m-f}\right)+\lambda_{m-f}} .
\end{array}
$$

$\delta_{p j}$ is the half length of the $j$ th source/sink for the inner/outer boundary; $s$ is for homogeneous reservoirs and $s f(s)$ is for naturally fractured reservoirs.

In order to consider the fracture conductivity, we use the results of Riley [21] here. The source function for the hydraulic fracture considering the fracture conductivity can be written by

$$
\begin{aligned}
& \bar{S}_{w D i}=\frac{\omega_{\text {in-out } i}}{\lambda_{\text {in-out } i}}\left\{\frac{\pi}{y_{e D i}} \widetilde{H}_{x 0}\right. \\
& +\frac{2}{y_{p i}} \sum_{n=1}^{\infty} \frac{1}{n} \widetilde{H}_{y n} \cos \frac{n \pi y_{w D i}}{y_{e D i}} \cos \frac{n \pi y_{D}}{y_{e D i}} \sin \frac{n \pi y_{p i}}{y_{e D i}} \\
& \left.+u_{y} \bar{f}\left(c_{f i D}\right)\right\}, \\
& u_{x} \bar{f}\left(c_{f i D}\right)=2 \pi \sum_{n=1}^{\infty} \frac{1}{n^{2} \pi^{2} c_{f i D}+2 \sqrt{n^{2} \pi^{2}+u_{x}}} \\
& +\frac{0.4063 \pi}{\pi\left(c_{f i D}+0.8997\right)+1.6252 u_{x}}
\end{aligned}
$$

where $u_{y} \bar{f}\left(c_{f i D}\right)$ is the finite-conductivity function for the $i$ th fracture.

Here we consider a MFHW with $n f$ hydraulic fractures. Both block 1 and block 2 have $n f / 2$ hydraulic fractures. Writing (2) at the center of all fractures and interface segments shown in Figure 2 yields the following set of $18 \times 2+n f$ linear equations which contain $2 \times(18 \times 2+n f)$ unknowns, $\bar{p}_{w D i}^{k}, \bar{p}_{e D j}^{k}, \bar{q}_{w D i}^{k}, \bar{q}_{e D j}^{k}$ :

$$
\begin{aligned}
& \bar{p}_{w D i}^{k}= {\left[\sum_{n=1}^{n f / 2} \bar{q}_{w D n}^{k} \cdot \bar{S}_{w D i w D n}^{k}\right] } \\
&+\left[\sum_{m=1}^{5} \bar{q}_{e D m}^{k} \cdot \bar{S}_{w D i e D m}^{k}\right], \\
& k=1,2, i=1,2, \ldots, \frac{n f}{2},
\end{aligned}
$$




$$
\begin{aligned}
& \bar{p}_{e D j}^{k}= {\left[\sum_{n=1}^{n f / 2} \bar{q}_{w D n}^{k} \cdot \bar{S}_{e D j w D n}^{k}\right] } \\
&+\left[\sum_{m=1}^{5} \bar{q}_{e D m}^{k} \cdot \bar{S}_{e D j e D m}^{k}\right], \\
& k=1,2, j=1,2, \ldots, 5, \\
& \bar{p}_{e D j}^{k}= \sum_{m=1}^{3} \bar{q}_{e D m}^{k} \cdot \bar{S}_{e D j e D m}^{k}, \quad k=4,5,7,9,10,12, j=1,2,3, \\
& \bar{p}_{e D j}^{k}= \sum_{m=1}^{2} \bar{q}_{e D m}^{k} \cdot \bar{S}_{e D j e D m}^{k}=0, \\
& k=3,6,8,11, j=1,2 .
\end{aligned}
$$

The pressure of different blocks for the same interfaces is equal and the flux of interfaces is continuous. Taking block 1 and block 2 as an example,

$$
\begin{aligned}
& \bar{p}_{e D 1}^{1}=\bar{p}_{e D 1}^{2} \text {; } \\
& \bar{q}_{e D 1}^{1}=-\bar{q}_{e D 1}^{2}, \\
& \bar{p}_{e D 2}^{1}=\bar{p}_{e D 2}^{2} \text {; } \\
& \bar{q}_{e D 2}^{1}=-\bar{q}_{e D 2}^{2}, \\
& \bar{p}_{e D 3}^{1}=\bar{p}_{e D 1}^{4} ; \\
& \bar{q}_{e D 3}^{1}=-\bar{q}_{e D 1}^{4}, \\
& \bar{p}_{e D 4}^{1}=\bar{p}_{e D 2}^{12} \text {; } \\
& \bar{q}_{e D 4}^{1}=-\bar{q}_{e D 2}^{12}, \\
& \bar{p}_{e D 5}^{1}=\bar{p}_{e D 1}^{10} \text {; } \\
& \bar{q}_{e D 5}^{1}=-\bar{q}_{e D 1}^{10}, \\
& \bar{p}_{e D 1}^{1}-\bar{p}_{e D 1}^{2}=\left\{\left[\sum_{n=1}^{n f / 2} \bar{q}_{w D n}^{1} \cdot \bar{S}_{e D 1 w D n}^{1}\right]\right. \\
& \left.+\left[\sum_{m=1}^{5} \bar{q}_{e D m}^{1} \cdot \bar{S}_{e D 1 e D m}^{1}\right]\right\} \\
& -\left\{\left[\sum_{n=1}^{n f / 2} \bar{q}_{w D n}^{2} \cdot \bar{S}_{e D 1 w D n}^{2}\right]\right. \\
& \left.+\left[\sum_{m=1}^{5} \bar{q}_{e D m}^{2} \cdot \bar{S}_{e D 1 e D m}^{2}\right]\right\}=\left[\sum_{n=1}^{n f / 2} \bar{q}_{w D n}^{1} \cdot \bar{S}_{e D 1 w D n}^{1}\right] \\
& -\left[\sum_{n=1}^{n f / 2} \bar{q}_{w D n}^{2} \cdot \bar{S}_{e D 1 w D n}^{2}\right]
\end{aligned}
$$

$$
\begin{aligned}
& +\sum_{m=1}^{2}\left[\bar{S}_{e D 1 e D m}^{1}+\bar{S}_{e D 1 e D m}^{2}\right] \cdot \bar{q}_{e D m}^{1}+\left[\sum_{m=3}^{5} \bar{q}_{e D m}^{1}\right. \\
& \left.\cdot \bar{S}_{e D 1 e D m}^{1}\right]-\left[\sum_{m=3}^{5} \bar{q}_{e D m}^{2} \cdot \bar{S}_{e D 1 e D m}^{2}\right]=0 .
\end{aligned}
$$

Ignoring the pressure depletion along the horizontal wellbore, the pressure of each fracture is approximately the same which is equal to the pressure of horizontal wellbore. Then we can have $n f$ additional equations:

$$
\begin{gathered}
\bar{p}_{w D 1}^{k}=\bar{p}_{w D 2}^{k}=\cdots=\bar{p}_{w D n f / 2}^{k}=\bar{p}_{w D}, \\
\text { for } k=1,2, \\
\bar{p}_{w D i}^{1}-\bar{p}_{w D i}^{2}=0, \quad \text { for } i=1,2, \ldots, \frac{n f}{2} .
\end{gathered}
$$

The sum of the flux of each fracture is equal to the well production rate:

$$
\sum_{k=1}^{2} \sum_{i=1}^{n f / 2} s \bar{q}_{w D i}^{k}=1
$$

The linear system defined by (7)-(15) now has $18+n f+1$ equations with $18+n f+1$ unknowns.

$$
A X=b .
$$

Eq. (16) can be solved by Gaussian elimination method. By solving (16), the instantaneous flux of each fracture and the wellbore pressure of MFHW with SRV in a rectangular tight oil reservoir with constant rate condition can be obtained. The whole workflow is shown in Figure 3. Here we take a MFHW with four fractures as an example and $A, X, b$ are shown in Appendix.

\section{Comparison and Validation}

In order to verify the accuracy of proposed model, we compare the results of semianalytical model with that of analytical model and trilinear flow model. Wang et al. [6] presented an analytical model for a MFHW in rectangular reservoirs by using the source function method and the principle of superposition. Ozkan et al. [8] utilized a trilinear flow model to study the MFHWs performance in unconventional reservoirs. Restricted by the models, neither analytical model nor trilinear flow model can simulate the SRV region accurately. For convenience of presentation and brevity, a relatively simple case which consists of a MFHW in a homogeneous rectangular reservoir is considered. By letting the properties of SRV and unstimulated region be equal, the model can be simplified. The calculated results are shown in Table 1 and plotted in Figure 4. From Figure 4 we can see that the results of semianalytical solution show a good fitting performance with the analytical solution for the same problem. The comparison between semianalytical 
TABLE 1: Comparison between analytical, trilinear flow model and semianalytical model results.

\begin{tabular}{|c|c|c|c|c|c|c|}
\hline \multirow{2}{*}{$t_{D}$} & \multicolumn{2}{|c|}{ Analytical model } & \multicolumn{2}{|c|}{ Trilinear flow model } & \multicolumn{2}{|c|}{ Semianalytical model } \\
\hline & $p_{w D}$ & $\mathrm{~d} p_{w D} / \mathrm{d} \ln t_{D}$ & $p_{w D}$ & $\mathrm{~d} p_{w D} / \mathrm{d} \ln t_{D}$ & $p_{w D}$ & $\mathrm{~d} p_{w D} / \mathrm{d} \ln t_{D}$ \\
\hline 0.001 & 0.061 & 0.015 & 0.065 & 0.016 & 0.061 & 0.015 \\
\hline 0.01 & 0.110 & 0.029 & 0.116 & 0.030 & 0.111 & 0.029 \\
\hline 0.1 & 0.209 & 0.060 & 0.222 & 0.067 & 0.209 & 0.060 \\
\hline 1 & 0.397 & 0.103 & 0.443 & 0.129 & 0.397 & 0.103 \\
\hline 10 & 0.663 & 0.122 & 0.836 & 0.219 & 0.662 & 0.122 \\
\hline 100 & 1.006 & 0.231 & 1.583 & 0.562 & 1.006 & 0.231 \\
\hline 1000 & 2.787 & 1.982 & 4.407 & 2.328 & 2.787 & 1.981 \\
\hline 10000 & 20.464 & 19.811 & 23.356 & 21.150 & 21.150 & 19.811 \\
\hline 100000 & 197.184 & 198.075 & 212.037 & 211.506 & 197.185 & 198.075 \\
\hline
\end{tabular}

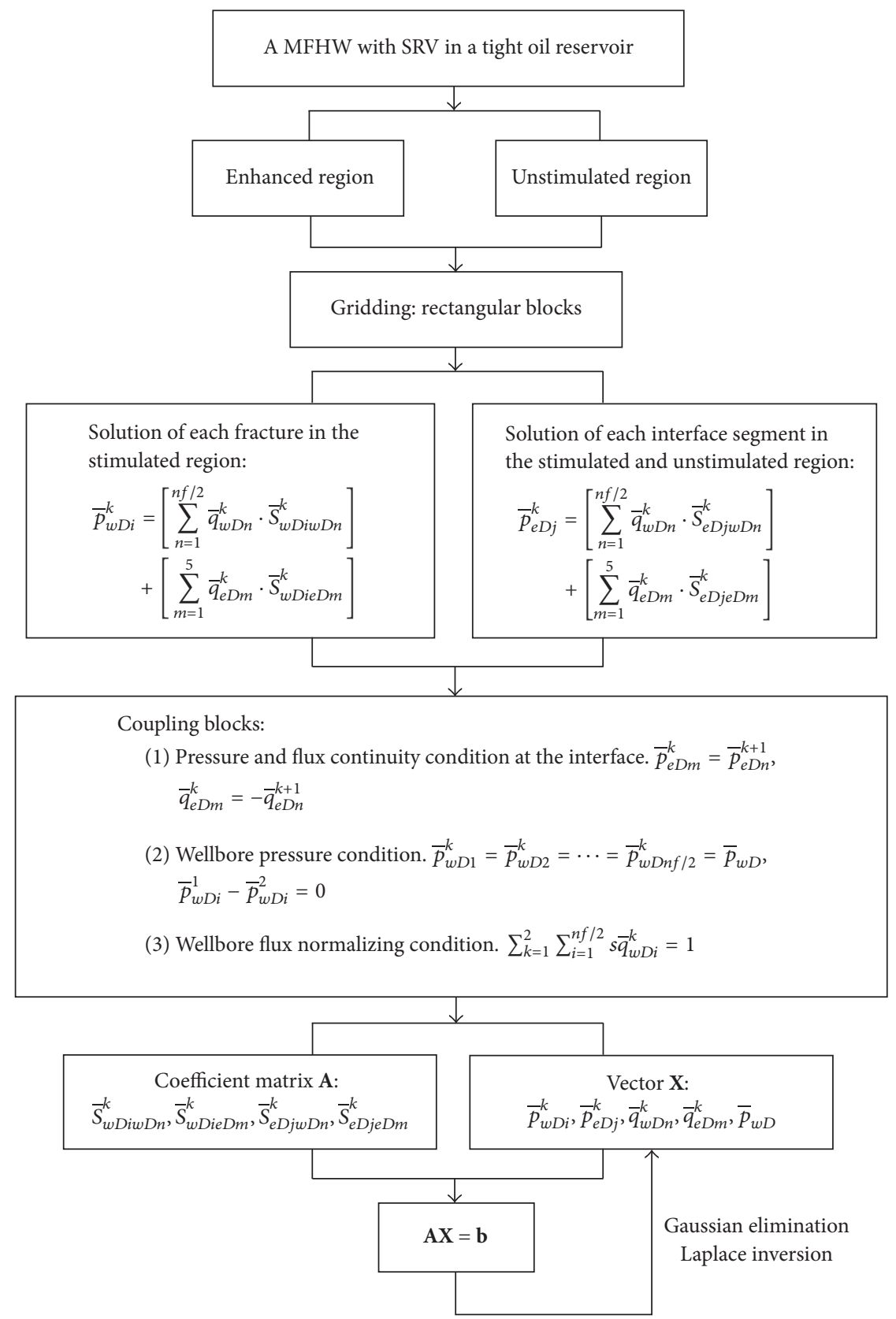

FIGURE 3: The work flow for modeling and solving process. 


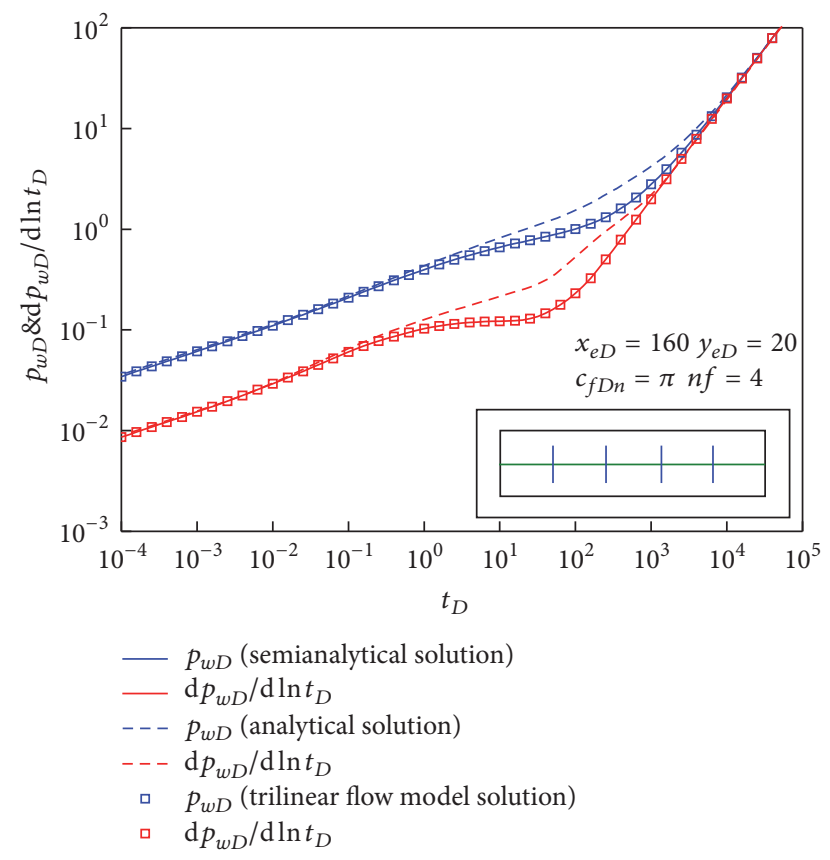

FIGURE 4: Calculation comparison between semianalytical model, analytical model, and trilinear flow model.

solution and trilinear flow model solution shows a good fitting performance in the early stage (linear flow). However, radial flow could not be seen by using trilinear flow model. MFHWs exhibit radial flow from beginning till the end which is usually misinterpreted as linear flow due to existence of linear flow as part of the radial flow. Thus, it is necessary to take nonlinear flow into account.

To access the accuracy of semianalytical model of MFHW with SRV in tight oil reservoir, a case is evaluated to investigate the pressure responses by using the commercial software Eclipse. The basic parameters are presented in Table 2. The reservoir block of $90 \times 21 \times 1$ is simulated with no flow boundaries. The enhanced region contains $44 \times 13 \times 1$ blocks which is shown in Figure 5. The horizontal well is located in center of reservoir horizontally and vertically to produce the oil effectively. Four hydraulic fractures are modeled with LGR technique to formulate thin blocks assigned with the properties of hydraulic fractures. Reservoir is fully penetrated by hydraulic fractures. Hydraulic fracture properties are assumed to be constant along the fracture. The flowing fluid is assumed to be single phase oil. Reservoir simulator is computed for 40 years of production with constant oil rate $30 \mathrm{~m}^{3} / \mathrm{D}$. The comparison results are shown in Figure 6. From the comparison results, it is shown that the agreements of the semianalytical solution and numerical solution are excellent.

\section{Results and Discussion}

4.1. Flow Regimes. The dimensionless pressure and pressure derivative type curves for a MFHW with SRV are plotted in Figure 7. As shown in Figure 7, seven flow stages can be identified.
TABLE 2: Input information for the case.

\begin{tabular}{lc}
\hline Reservoir lateral length $(\mathrm{m})$ & 933 \\
Initial pressure $(\mathrm{MPa})$ & 20.29 \\
Wellbore radius $(\mathrm{m})$ & 0.1 \\
Reservoir compressibility $\left(\mathrm{MPa}^{-1}\right)$ & 0.02 \\
Matrix porosity & 0.125 \\
Oil viscosity $(\mathrm{mPa} \cdot \mathrm{s})$ & 4 \\
Fracture spacing $(\mathrm{m})$ & 59.25 \\
Fracture half-length $(\mathrm{m})$ & 50 \\
Fracture permeability $\left(\mu \mathrm{m}^{2}\right)$ & 2.5 \\
Enhanced region permeability $\left(\mu \mathrm{m}^{2}\right)$ & 0.06 \\
Unstimulated region permeability $\left(\mu \mathrm{m}^{2}\right)$ & 0.01 \\
\hline
\end{tabular}

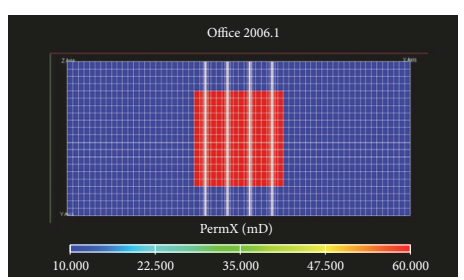

FIGURE 5: Numerical model of a multiple-fractured horizontal well with SRV.

(1) Bilinear flow between the hydraulic fractures and induced fractures: In this stage, the pressure derivative curve has a straight line with slope equal to $1 / 4$. Fluid flows through hydraulic fractures to wellbore and from induced fractures to hydraulic fractures simultaneously. This stage could be identified only if the fracture conductivity is relatively low.

(2) Linear flow near the hydraulic fractures: During this period, each fracture produces independently. The pressure and pressure derivative curves are both straight lines with slope equal to $1 / 2$.

(3) Interporosity flow between the induced fractures and matrix: In this stage, the fluid flows from the matrix system to the induced fractures system. The pressure derivative curves show "U" shape.

(4) Radial flow around the hydraulic fractures: If the pressure derivative curve shows the $1 / 2 n f$ ( $n f$ is the number of fractures), the radial flow region will be observed. In this stage, radial flow occurs directly from the enhanced region to individual fractures.

(5) Transition flow near the enhanced region boundaries (Interporosity flow between the enhanced region and unstimulated region): In this region, the permeability of enhanced region is higher than that of the unstimulated region. The fluid in the enhanced region can reach the wellbore quickly; however, the formation in the unstimulated region can not provide enough fluid supply. The pressure derivative curves rise up which shows the similar characteristics of the weak supply or closed boundary flow.

(6) Mid-linear flow around the horizontal well: Compared to the transition flow, the slopes of both pressure and pressure derivative curves are relatively small. Fluid flows from the unstimulated region to the enhanced region. 


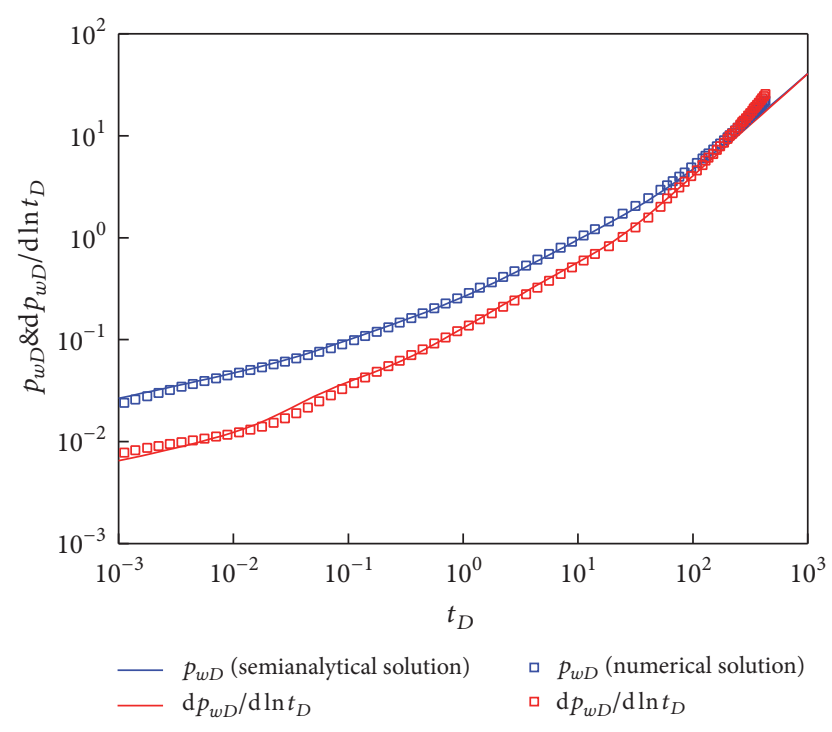

FIGURE 6: Calculation comparison between semianalytical model and numerical model.

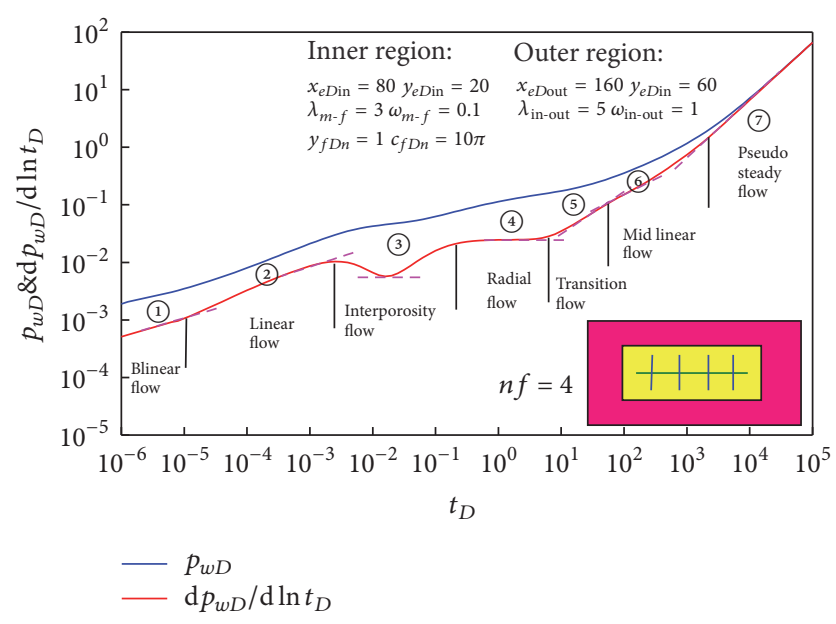

FIGURE 7: The dimensionless pressure and pressure derivative curves of a MFHW with SRV in a tight oil reservoir.

(7) Pseudo steady flow: The segment has a unit slope straight line on both pressure and pressure derivative curves. This flow period occurs when the pressure wave reaches the reservoir boundary.

\subsection{Effect of Sensitive Parameters on Type Curves}

4.2.1. Interporosity Flow Factor between the Inner and Outer Region $\left(\lambda_{\text {in-out }}\right)$. Figure 8 shows the effect of interporosity flow factor between the inner and outer region $\lambda_{\text {in-out }}$ on the type curves. $\lambda_{\text {in-out }}$ is the mobility ratio between the inner and outer region. In Figure 8(a) we can see that the interporosity flow factor between the inner and outer region can affect all the flow regimes. With the increase of $\lambda_{\text {in-out}}$, the dimensionless pressure and pressure derivative decrease as a whole. It can be seen from the dimensionless pressure derivative curves that when the mobility between the inner and outer region is the same $\left(\lambda_{\text {in-out }}=1\right)$ it will not create transition flow, but, instead, mid-linear flow. When the effect of hydraulic fracturing is good, the permeability of induced fractures system in the inner region is far higher than that of the formation in the outer region. The fluid in the inner region can reach the wellbore quickly; however, the formation in the outer region can not provide enough fluid supply. The pressure derivative curves rise up which shows the similar characteristics of the weak supply or closed boundary flow. The time of radial flow period in the region with higher mobility is shorter than that with lower mobility. It is known that radial flow can cause large pressure depletion under the same rate, and thus it is better to increase the scale of hydraulic fracturing as much as possible to improve the mobility of the inner region. Figures 8 (b) and 8 (c) show that the flux of fracture at the edge is higher than that at the center. This is because the fracture at the edge has a bigger drainage area. The time of transition flow in the region with higher mobility is shorter than that with lower mobility and the time of mid-linear flow in the region with higher mobility is longer than that with lower mobility. The larger the $\lambda_{\text {in-out }}$, the greater the differences between the flux of fracture at the edge and center and between the flux of different interfaces.

4.2.2. Hydraulic Fracturing Degree (Storage Ratio $\omega_{m-f}$ and Interporosity Flow Factor $\lambda_{m-f}$ ). Figure 9 shows that the storage ratio $\omega_{m-f}$ and interporosity flow factor $\lambda_{m-f}$ affect the degree and time of interporosity flow between induced fractures system and matrix, respectively. Small $\omega_{m-f}$ means that the difference between the storage capacity of induced fractures system and matrix is great. Most of the fluid is stored in the matrix rather than the induced fractures system and the interporosity flow behaves more obviously. The dimensionless pressure derivative curve sinks down at the intermediate time. $\lambda_{m-f}$ reflects the ability of the fluid to flow from the matrix to the induced fractures system. The larger the $\lambda_{m-f}$ is, the earlier the interporosity flow will happen. Therefore, increasing the degree of hydraulic fracturing is beneficial to the production.

4.2.3. The Size and Shape of Stimulated Reservoir Volume. Figures 10-11 show the effects of size and shape of SRV on type curves. It can be seen from Figures 10-11 that both the size and shape of SRV will affect the radial flow and transition flow. A small size of SRV will shorten the time of radial flow and make transition flow occur early. Comparing with the three models presented in Figure 10(a), we can see that with the size of SRV increasing, the increasing trend of dimensionless pressure gradually slows down. This is mainly because the reserves controlled by a single well are very limited, and there is no sense in increasing the stimulated reservoir volume without limitation. At the same time, increasing the size of SRV will also increase the difficulty and cost of fracturing. From Figure 10(b) we can see that the larger the size of SRV, the greater the fracture flux difference between the edge and center. As shown in Figure 11, the dimensionless pressure with square shape of SRV is higher than that with rectangular one, which means that the square shape of SRV will cause a small pressure depletion under the same rate. In addition, with the 


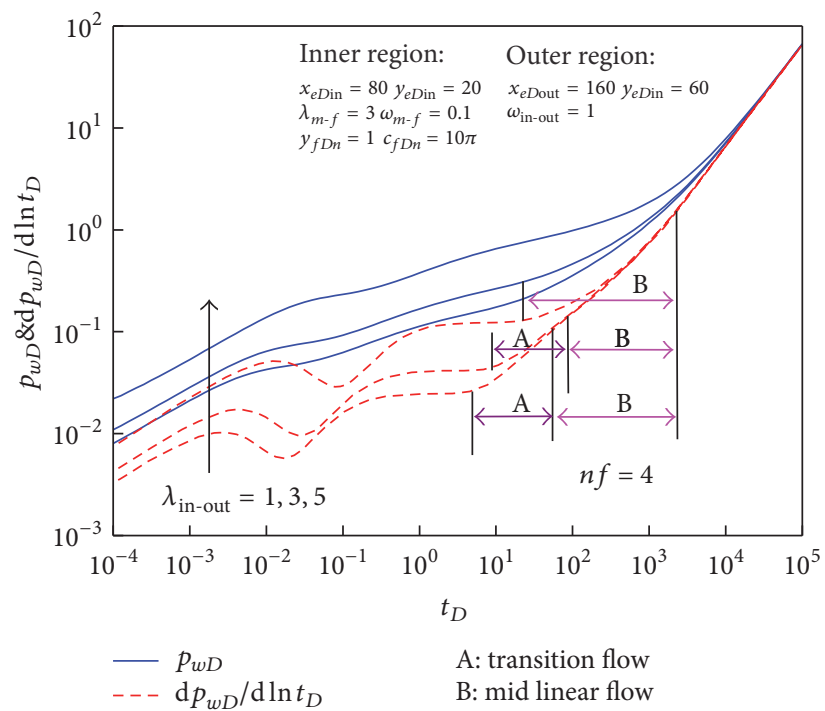

(a) Dimensionless pressure and pressure derivative curves

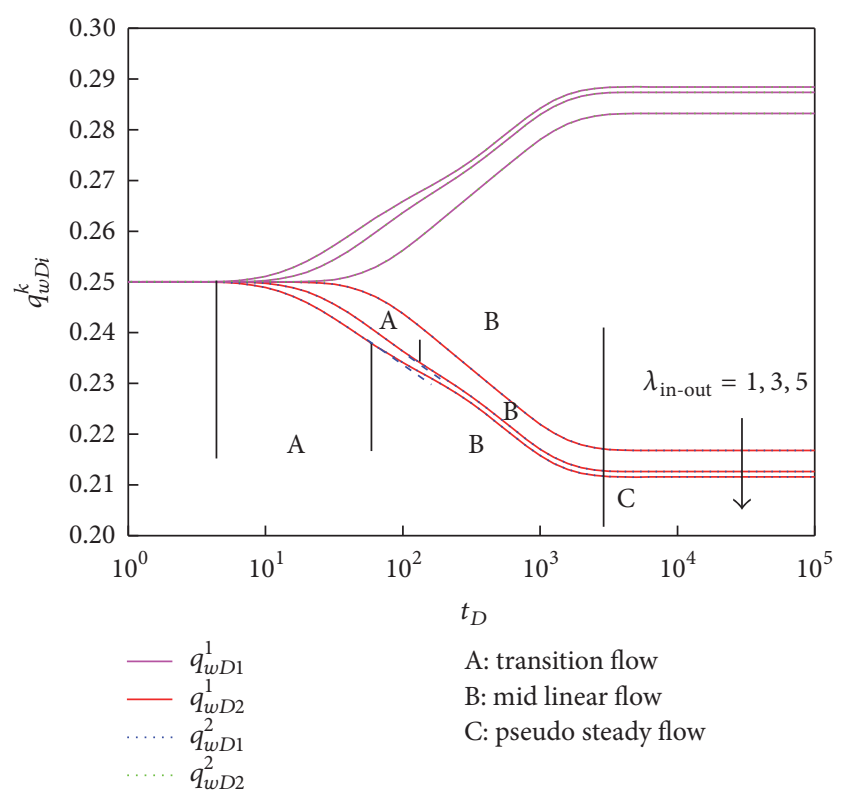

(b) Flux of each fracture

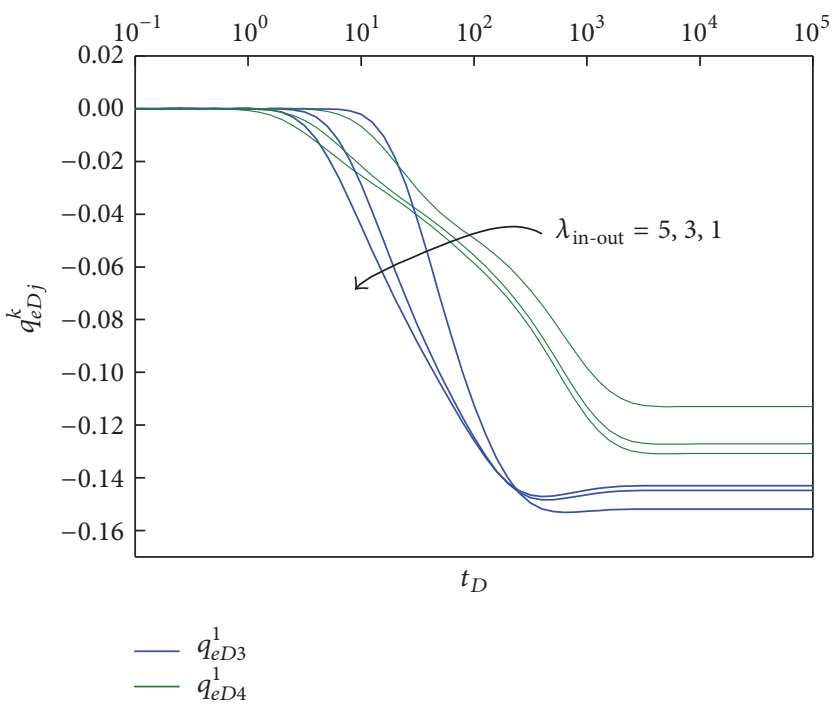

(c) Flux of each interface

FIGURE 8: The effect of interporosity flow factor on type curves (inner and outer region).

increase of length-width ratio of SRV, both the dimensionless pressure and the fracture flux difference between the edge and center increase. It is because in the early period the flow only occurs in the hydraulic fractures and induced fractures near the horizontal wellbore which is not influenced by the shape of SRV. With the process of production, the pressure wave spreads to the edges of enhanced region, and the producing degree of formation with larger effective stimulated reservoir volume is much higher. Therefore, not only the size but also the shape of SRV should be taken into account in the fracturing design.

4.2.4. Fracture Distribution. Figure 12 shows the effect of fracture distribution on type curves. As shown in Figure 12, the fracture distribution can mainly affect the flow characteristics of radial flow and transition flow. With the increase of fracture distribution heterogeneity, the pressure depletion becomes large. This is because the drainage area of each fracture is relatively small. If the fractures are very close to the enhanced region boundaries, second radial flow will occur once the pressure wave spreads to the nearest boundaries, and second transition flow will happen after the pressure wave spreads to the far boundaries. Therefore, it is necessary to make the hydraulic fractures distribute uniformly as far as possible.

4.2.5. Fracture Conductivity. Figure 13 shows the effect of fracture conductivity on type curves. From the pressure derivative curves we can see that the fracture conductivity mainly affects flow characteristics of bilinear flow, linear flow, 


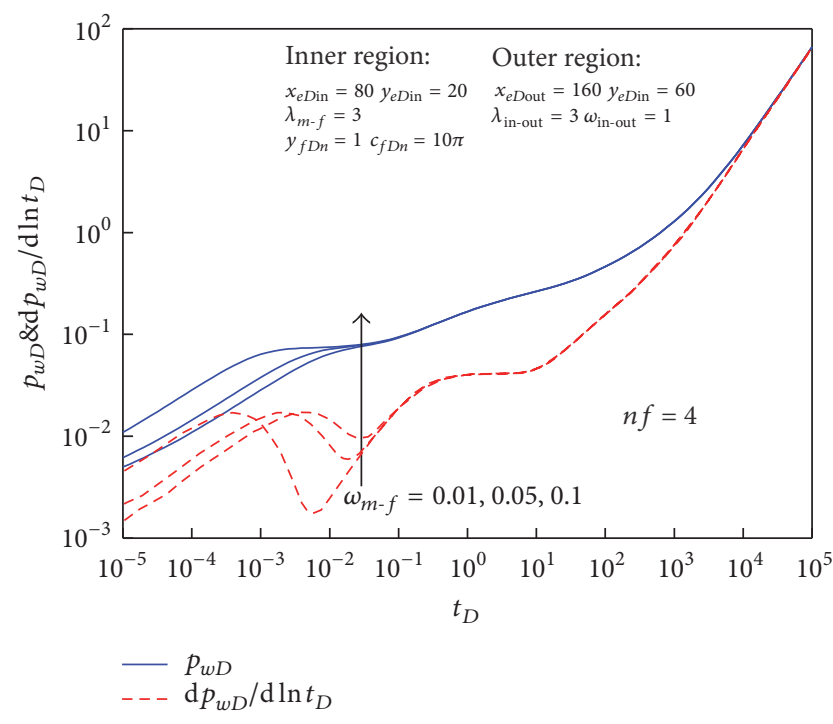

(a) Storage ratio

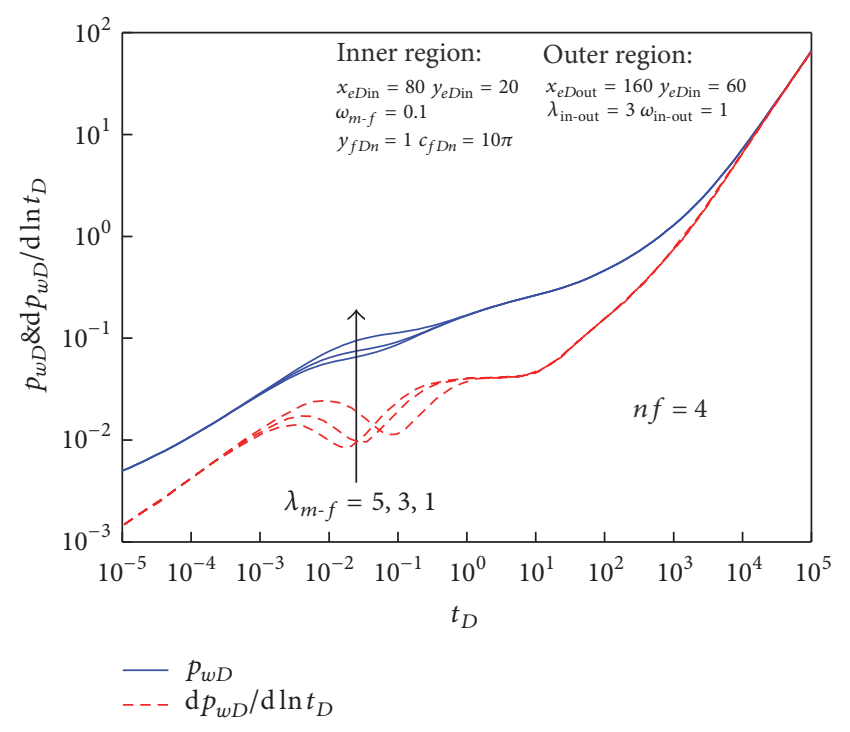

(b) Interporosity flow factor

FIgURE 9: The effect of hydraulic fracturing degree on type curves.

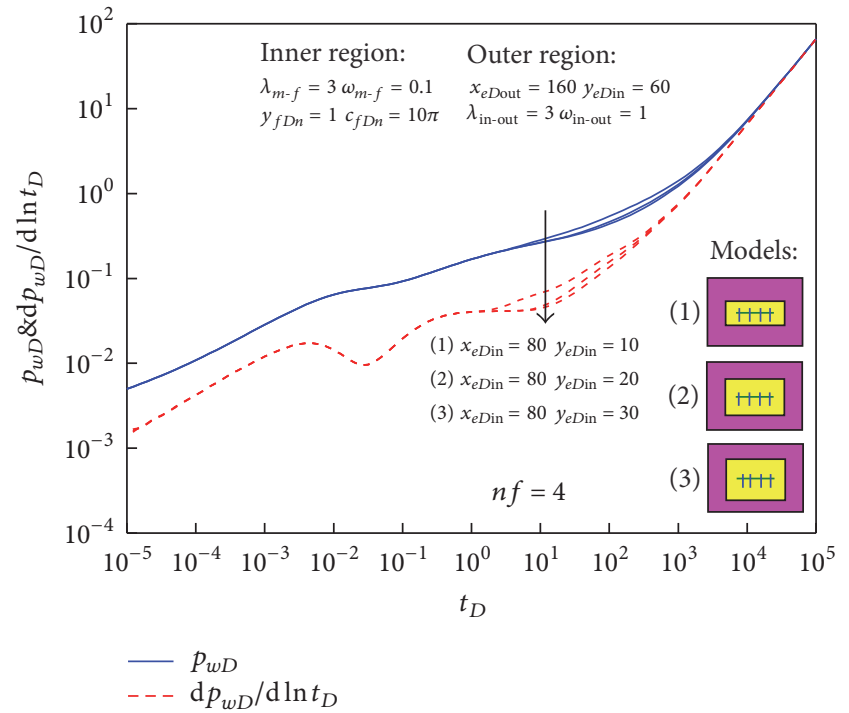

(a) Dimensionless pressure and pressure derivative curves

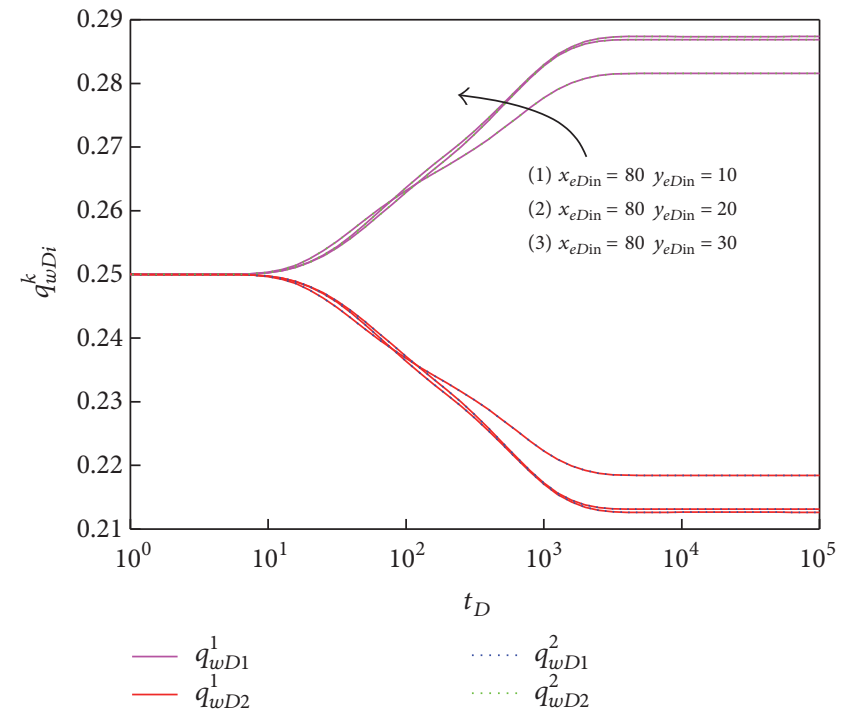

(b) Flux of each fracture

FIGURE 10: The effect of size of SRV on type curves.

and interporosity flow. Due to the high fracture conductivity, the pressure gradient near the hydraulic fracture is high. Fluid flows quickly from the induced fractures into the hydraulic fractures, which makes the linear flow and interporosity flow occur early.

4.2.6. Fracture Length. As shown in Figure 14, the fracture length can affect bilinear flow, linear flow, interporosity flow, and radial flow. With the increase of fracture length, the dimensionless pressure and pressure derivative decrease gradually. On the contrary to the conventional reservoirs, the effect of fracture length is greater than that of fracture conductivity on the MFHWs with SRV in tight oil reservoirs. As the fracture length increases, more and more induced fractures in the enhanced region are connected with hydraulic fractures effectively, which can form a larger supply area and improve the overall yield. Longer fracture length will increase the time of interporosity flow and shorten the time of radial flow. In conventional fractured reservoirs, the fracture conductivity is dominant, whereas in volume fractured tight oil reservoirs the effect of fracture length is contrary to normal expectation. Therefore, in order to achieve the desired effect of volume fracturing design, a suitable length of the artificial hydraulic fractures should also be ensured. 


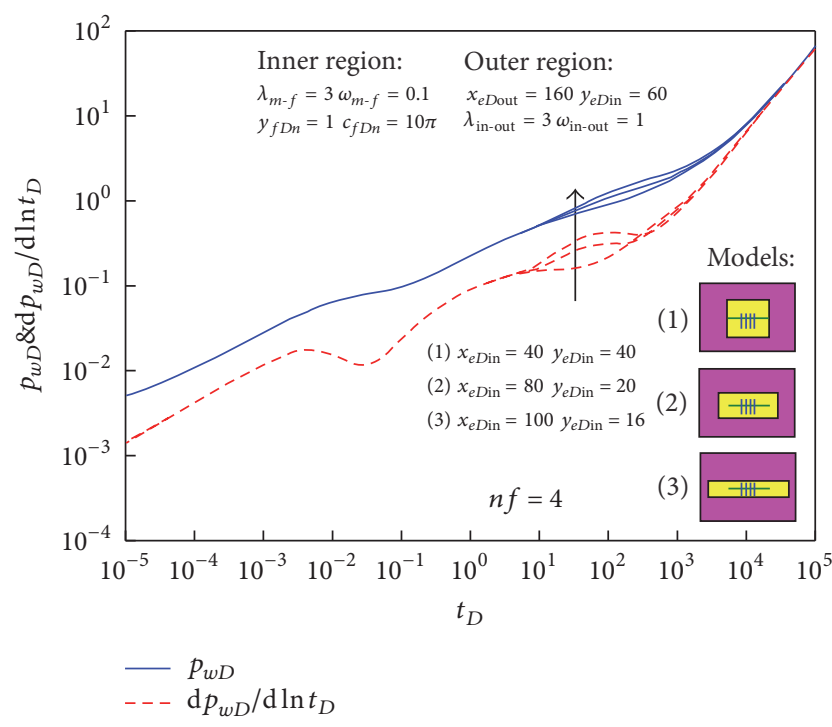

(a) Dimensionless pressure and pressure derivative curves

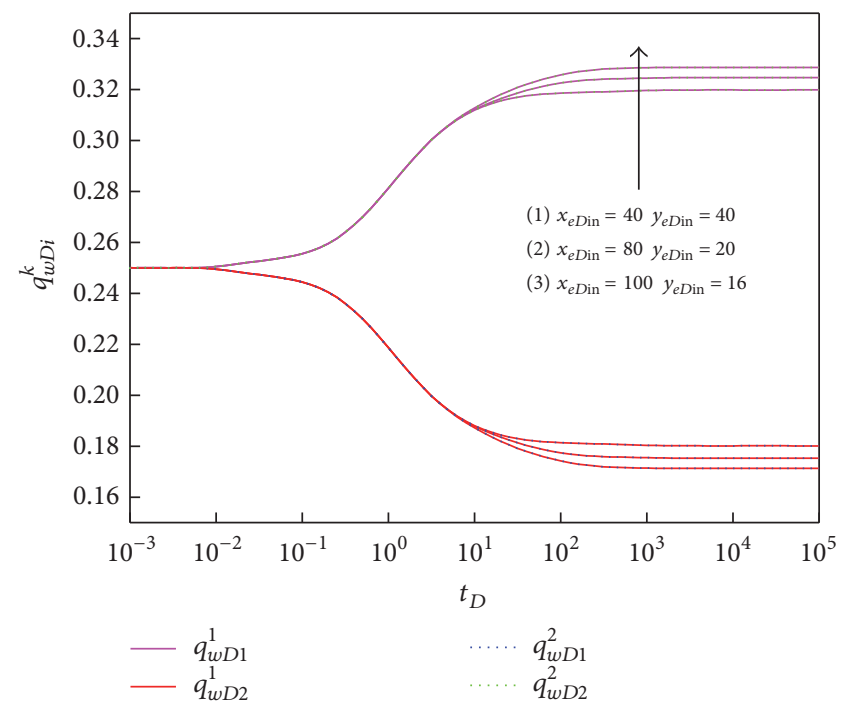

(b) Flux of each fracture

FIGURE 11: The effect of shape of SRV on type curves.

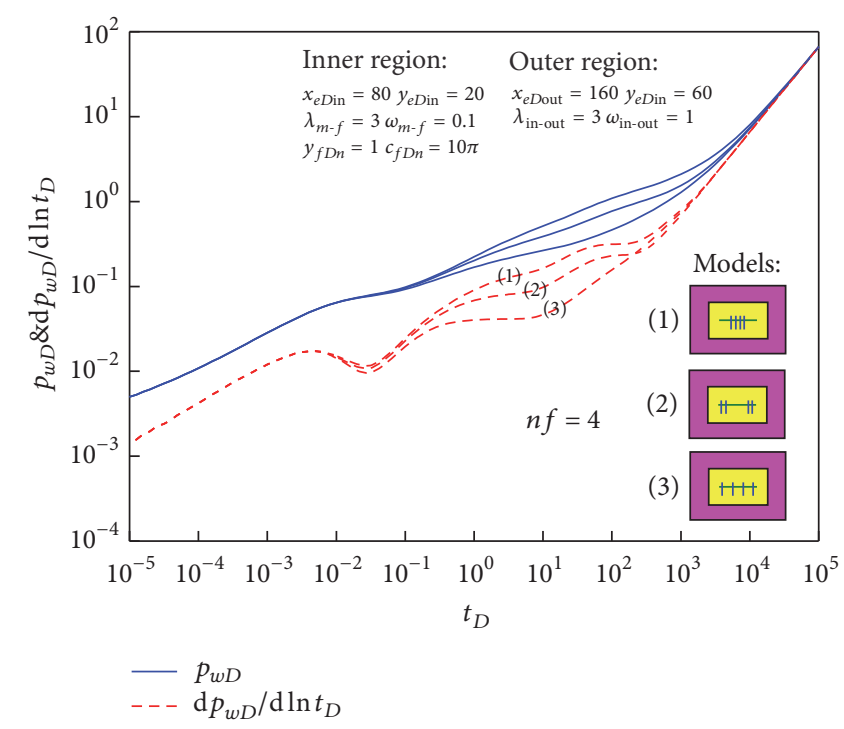

FIgURE 12: The effect of fracture distribution on type curves.

\section{Field Applications}

Type curve matching is an effective way to evaluate the parameters of reservoir and fracture. The specific processes are presented as follows.

Step 1. Plot the curve of dimensionless pressure $\left(p_{w D}\right)$ values versus test time $\left(t_{D}\right)$ on a log-log graph.

Step 2. Obtain the best match of the data with one of type curves.

Step 3. Read a point (e.g., $t_{D}, p_{w D}, c_{f D}$ ) from the matched type curve. By using the defined equations of dimensionless parameter in (17)-(20), the reservoir and fracture parameters can be calculated.

$$
\begin{aligned}
k & =\frac{1.842 \times 10^{-3} p_{w D} q \mu B}{\left(p_{i}-p_{j}\right) h}, \\
L_{f} & =\sqrt{\frac{3.6 k t}{\phi \mu c_{t} t_{D}}}, \\
k_{f} & =\frac{k L_{f} c_{f D}}{w_{f}}, \\
\lambda_{\text {in-out } j} & =\frac{(k / \mu)_{j}}{(k / \mu)_{\text {ref }}} .
\end{aligned}
$$




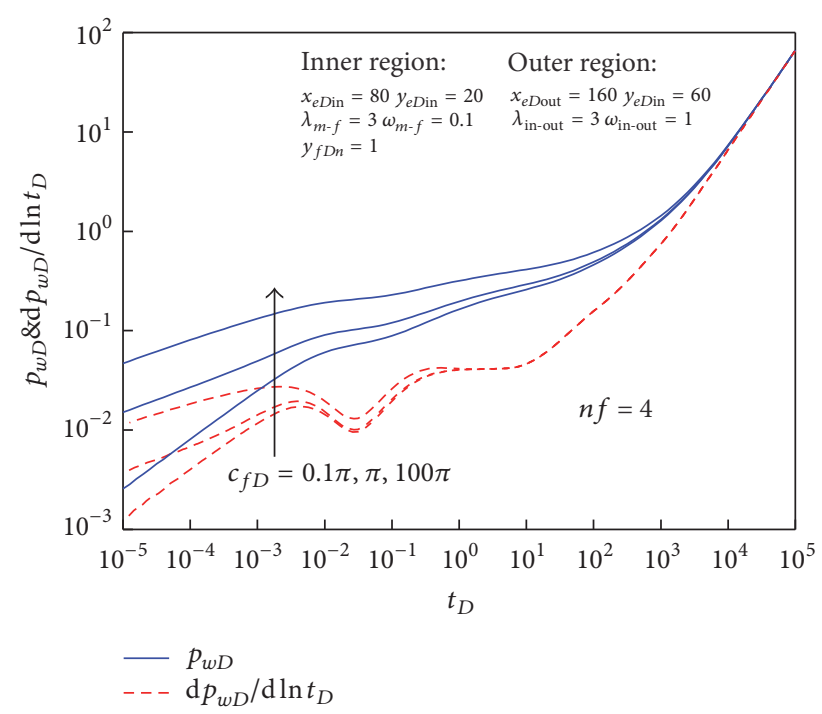

FIGURE 13: The effect of fracture conductivity on type curves.

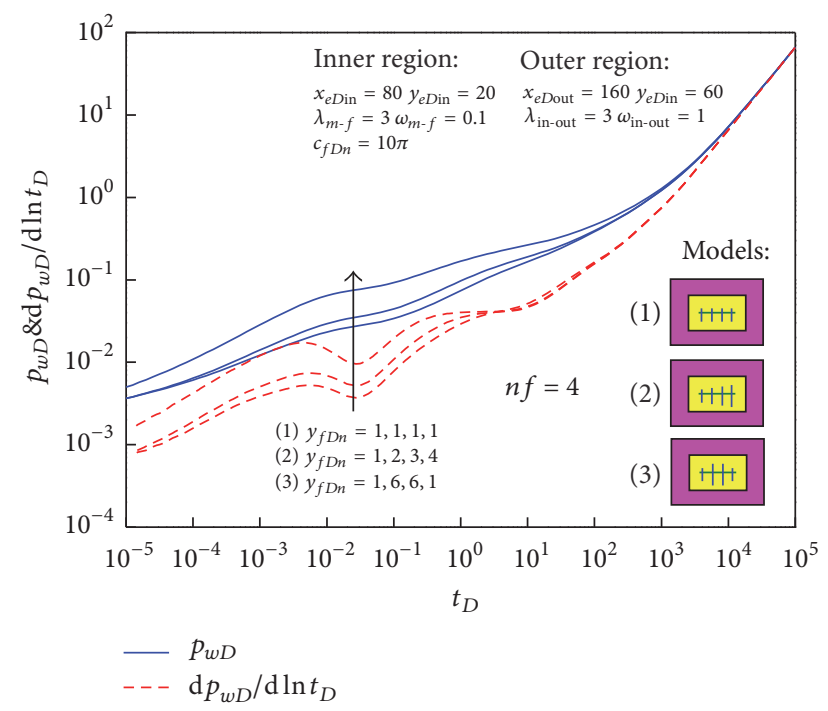

Figure 14: The effect of fracture length on type curves.

Well $A$ is a horizontal well with 38 hydraulic fractures in Bakken formation in the Williston Basin. The length of well is approximately $2926.08 \mathrm{~m}$. Since hydraulic fracturing methods with a high number of stages have not been widely used so far, the production history of well $A$ is shorter than two years. The type curve matching plot is shown in Figure 15. From Figure 15 we can see that the pressure derivative curve starts to bend in the transition flow period; however, it could not be seen by using the traditional model without SRV. The calculation processes are presented as follows:

\section{Reservoir Data}

$$
\begin{aligned}
\phi \mu c_{t} & =9.80841 \times 10^{-2} \mathrm{mpa} \cdot \mathrm{s} / \mathrm{Mpa}, \\
\frac{\mu B}{h} & =0.935369 \mathrm{mpa} \cdot \mathrm{s} / \mathrm{m}, \\
t & =55 \text { days }
\end{aligned}
$$

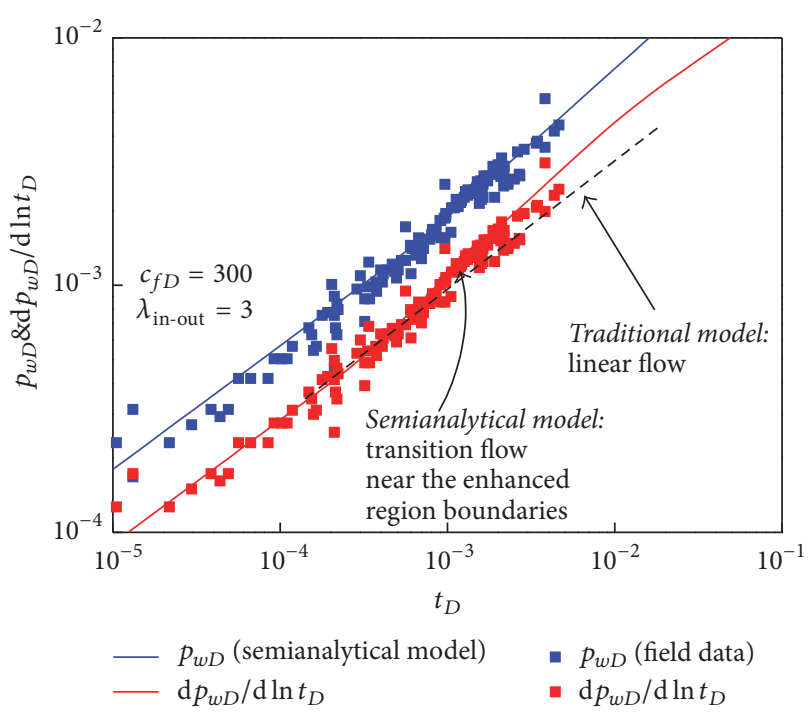

FIGURE 15: Type curve matching plot for field data.

$$
\begin{aligned}
w_{f} & =0.003 \mathrm{~m} \\
\frac{p_{i}-p_{w}}{q} & =0.246036 \mathrm{Mpa} /\left(\mathrm{m}^{3} \cdot \mathrm{day}^{-1}\right) .
\end{aligned}
$$

Match Point

$$
\begin{aligned}
t_{D} & =1.97459 \times 10^{-4}, \\
p_{w D} & =6.71136 \times 10^{-4}, \\
c_{f D} & =300 .
\end{aligned}
$$

Step 1. Calculate $k_{\text {in }}$ (the permeability of enhanced region) from (17):

$$
\begin{aligned}
k_{\text {in }} & =\frac{1.842 \times 10^{-3} \times 6.71136 \times 10^{-4} \times 0.935369}{0.246036} \\
& =0.0047 \times 10^{-3} \mu \mathrm{m}^{2} .
\end{aligned}
$$

Step 2. Calculate $L_{f}$ (the half length of hydraulic fracture) from (18):

$$
\begin{aligned}
L_{f} & =\sqrt{\frac{3.6 \times 0.0047 \times 10^{-3} \times 55 \times 24}{9.80841 \times 10^{-2} \times 1.97459 \times 10^{-4}}} \\
& =33.9587 \mathrm{~m} .
\end{aligned}
$$

Step 3. Calculate $k_{f}$ (the permeability of hydraulic fracture) from (19):

$$
k_{f}=\frac{0.0047 \times 10^{-3} \times 33.9587 \times 300}{0.003}=15.9606 \mu \mathrm{m}^{2} .
$$

Step 4. Calculate $k_{\text {out }}$ (the permeability of unstimulated region) from (20):

$$
k_{\text {out }}=\frac{k_{\text {in }}}{\lambda_{\text {in-out }}}=\frac{0.0047 \times 10^{-3}}{3}=0.0016 \times 10^{-3} \mu \mathrm{m}^{2} .
$$


Chu et al. [22] summarized the statistics of the Bakken wells. The permeability of enhanced region is $0.0027 \times 10^{-3} \sim$ $0.0122 \times 10^{-3} \mu \mathrm{m}^{2}$ and the half length of the hydraulic fracture is $27.1272 \sim 75.2856 \mathrm{~m}$. The results of semianalytical model are in this range, which indicates that the proposed model can provide more accurate dynamic parameters for MFHWs with SRV.

\section{Conclusions}

A practical semianalytical model is proposed for MFHWs with SRV in tight oil reservoirs and transient pressure and pressure derivative curves are also established. The principal contributions in our work are summarized below:

(1) Using the source function the semianalytical model can easily consider the nonlinear flow around hydraulic fracture tips and accurately describe the flow characteristics of MFHWs with SRV in tight oil reservoirs.

(2) Seven possible characteristic flow periods can be identified based on the type curves of MFHWs with SRV in tight oil reservoir: (1) bilinear flow; (2) linear flow; (3) interporosity flow; (4) radial flow; (5) transition flow; (6) mid-linear flow; (7) pseudo steady flow.

(3) The effects of relevant parameters on type curves including interporosity flow factor between inner and outer region, hydraulic fracturing degree, size and shape of SRV, fracture distribution, fracture conductivity, and fracture length are also analyzed.
(4) Analysis results reveal that when the mobility of inner region is higher than that of outer region, transition flow occurs. The larger the size and degree of SRV are, the better the development is. When the size of SRV is constant, the producing degree of reservoir with large effective stimulated reservoir volume is higher. It is better to make the hydraulic fractures distribute uniformly so as to increase the drainage area of each hydraulic fracture as far as possible. Compared to the conventional fracturing, the development effect of volume fracturing is influenced by the length of main fracture rather than the conductivity.

(5) In the field applications, traditional models such as analytical, multilinear models could not predict pressure response characteristics in the interporosity flow period between the enhanced region and unstimulated region accurately. The semianalytical model in this paper can be used to provide more accurate dynamic parameters which are important for efficient reservoir development.

\section{Appendix}

\section{Solution of the Linear System of Equations}

The linear system in (7)-(15) is in the matrix-vector form, $A X=b$, as shown in (A.4). The components of the coefficient matrix, $A=\left\{A_{1}, A_{2}\right\}$, are given by

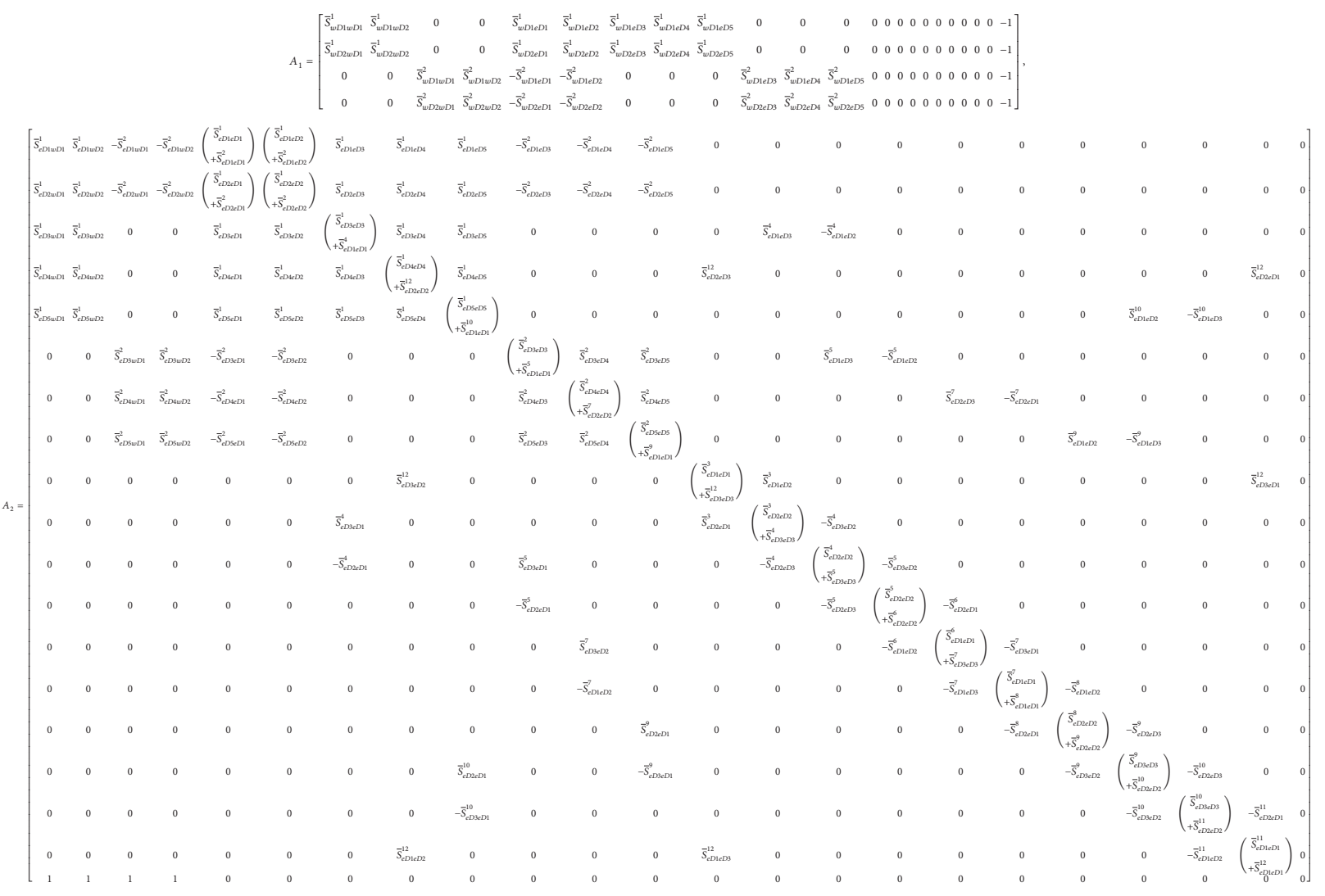


The solution vector, $X=\left[x_{1}, x_{2}\right]$, has the following components:

$$
\begin{aligned}
& x_{1}=s \bar{q}_{w D 1}^{1} s \bar{q}_{w D 2}^{1} s \bar{q}_{w D 1}^{2} s \bar{q}_{w D 2}^{2} \\
& x_{2} \\
& =s \bar{q}_{e D 1}^{1} \quad s \bar{q}_{e D 2}^{1} \quad s \bar{q}_{e D 3}^{1} \quad s \bar{q}_{e D 4}^{1} s \bar{q}_{e D 5}^{1} \quad s \bar{q}_{e D 3}^{2} s \bar{q}_{e D 4}^{2} s \bar{q}_{e D 5}^{2} s \bar{q}_{e D 1}^{3} s \bar{q}_{e D 2}^{3} s \bar{q}_{e D 2}^{4} s \bar{q}_{e D 2}^{5} s \bar{q}_{e D 1}^{6} s \bar{q}_{e D 1}^{7} s \bar{q}_{e D 2}^{8} \quad s \bar{q}_{e D 3}^{9} \quad s \bar{q}_{e D 3}^{10} \quad s \bar{q}_{e D 1}^{11} s \bar{p}_{w D}
\end{aligned}
$$

The components of the right-hand-side vector, $b=$ $\left[b_{1}, b_{2}\right]$, are

$$
b_{1}=\left[\begin{array}{llll}
0 & 0 & 0 & 0
\end{array}\right] \text {, }
$$

$b_{2}=\left[\begin{array}{lllllllllllllllllll}0 & 0 & 0 & 0 & 0 & 0 & 0 & 0 & 0 & 0 & 0 & 0 & 0 & 0 & 0 & 0 & 0 & 0 & 1\end{array}\right]$,

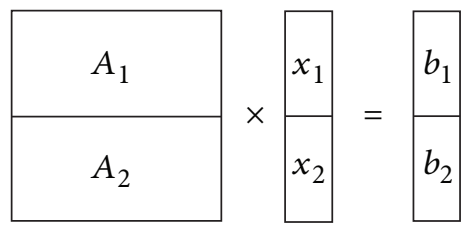

\section{Nomenclature}

A: Coefficient matrix

$b$ : Right-hand-side vector

$B$ : Formation volume factor

$c_{t j}$ : Total compressibility of the $j$ th block, $\mathrm{Mpa}^{-1}$

$S$ : $\quad$ Source function

$\alpha_{p}$ : Constant for pressure

$\alpha_{t}: \quad$ Constant for time

$h$ : Reservoir thickness, $\mathrm{m}$

$k_{f i}$ : The $i$ th fracture permeability, md

$\lambda_{\text {ref }}$ : Characteristic interporosity flow factor, desirable minimum of interporosity flow coefficient of all the blocks

$\eta_{\text {ref }}$ : Diffusivity constant, desirable minimum of diffusivity constant of all the blocks

$k_{i}$ : The $i$ th block permeability, md

$L_{f}$ : Characteristic length, $\mathrm{m}$, desirable minimum half length of artificial hydraulic fracture

$w_{f i}$ : Width of the fracture, $m$

$y_{f i}$ : Half length of the $i$ th fracture segment, $m$

$p$ : $\quad$ Reservoir pressure, $\mathrm{Mpa}$

$p_{i}$ : Initial reservoir pressure, $\mathrm{Mpa}$

$q$ : $\quad$ Production rate, $\mathrm{m}^{3} / \mathrm{D}$

$s$ : Laplace-transformation parameter

$t: \quad$ Time, days

$x: \quad x$-coordinate, $\mathrm{m}$

$X: \quad$ Solution vector

$y$ : $y$-coordinate

$\phi: \quad$ Reservoir porosity, fraction

$\lambda_{m-f}$ : Interporosity flow factor between the matrix and induced fractures

$\omega_{m-f}$ : Storage ratio between the matrix and induced fractures

$\mu: \quad$ Fluid viscosity, mpa.s

$c_{f D}$ : Dimensionless artificial hydraulic fracture conductivity

$t_{D}$ : Dimensionless time.

\section{Subscripts and Superscripts}

$\begin{array}{ll}D: & \text { Dimensionless } \\ e: & \text { Boundary } \\ k: & \text { Number of block } \\ j: & \text { Interface segment } \\ i: & \text { Number of fractures } \\ w: & \text { Wellbore } \\ \text { in-out: } & \text { Inner region and outer region } \\ m-f: & \text { Matrix and induced fractures. }\end{array}$

\section{Conflicts of Interest}

The authors declare that there are no conflicts of interest regarding the publication of this paper.

\section{Acknowledgments}

This paper was supported by the Fundamental Research Funds for the Central Universities.

\section{References}

[1] I. Brohi, M. Pooladi-Darvish, and R. Aguilera, "Modeling fractured horizontal wells as dual porosity composite reservoirs - application to tight gas, shale gas and tight oil cases," in Proceedings of the Society of Petroleum Engineers Western North American Regional Meeting 2011, pp. 68-89, May 2011.

[2] W. Zhou, S. Gupta, R. Banerjee, B. Poe, J. Spath, and M. Thambynayagam, "Production forecasting and analysis for unconventional resources," in Proceedings of the International Petroleum Technology Conference, Beijing, China, 2013.

[3] C. Jia, M. Zheng, and Y. Zhang, "Unconventional hydrocarbon resources in China and the prospect of exploration and development," Petroleum Exploration and Development, vol. 39, no. 2, pp. 139-146, 2012.

[4] P. H. Nelson, "Pore-throat sizes in sandstones, tight sandstones, and shales," AAPG Bulletin, vol. 93, no. 3, pp. 329-340, 2009.

[5] L. Xu, Y. Shi, C. Xu, Y. Yang, H. Li, and Z. Chai, "Influences of feldspars on the storage and permeability conditions in tight oil reservoirs: a case study of Chang-6 group, Ordos Basin," Petroleum Exploration and Development, vol. 40, no. 4, pp. 481487, 2013.

[6] X. Wang, W. Luo, X. Hou, and J. Wang, "Transient pressure analysis of multiple-fractured horizontal wells in boxed reservoirs," Petroleum Exploration and Development, vol. 41, no. 1, pp. 74-78, 2014.

[7] M. J. Mayerhofer, E. Lolon, and N. R. Warpinski, "What is stimulated reservoir volume?" SPE Production \& Operations, vol. 25, no. 1, pp. 89-98, 2010 (Polish). 
[8] E. Ozkan, M. Brown, R. Raghavan, and H. Kazemi, "Comparison of fractured horizontal-well performance in conventional and unconventional reservoirs," in Proceedings of the SPE Western Regional Meeting, pp. 345-360, Society of Petroleum Engineers, March 2009.

[9] E. Ozkan, M. Brown, R. Raghavan, and H. Kazemi, "Comparison of fractured-horizontal-well performance in tight sand and shale reservoirs," SPE Reservoir Evaluation and Engineering, vol. 14, no. 2, pp. 248-259, 2011.

[10] M. Brown, E. Ozkan, R. Raghavan, and H. Kazemi, "Practical solutions for pressure- transient responses of fractured horizontal wells in unconventional shale reservoirs," SPE Res Eval \& Eng, vol. 14, no. 6, Article ID 125043, pp. 663-676, 2011.

[11] E. Stalgorova and L. Mattar, "Practical analytical model to simulate production of horizontal wells with branch fractures," in Proceedings of the SPE Canadian Unconventional Resources Conference, Calgary, Canada, November 2012.

[12] C. J. Guo, J. Zeng, X. Z. Wang, and F. H. Zeng, "Analytical model for multifractured horizontal wells in heterogeneous shale reservoirs," in Proceedings of the Presented at the SPE Asia Pacific Oil \& Gas Conference and Exhibition, SPE-182422-MS, Perth, Australia, 2016.

[13] S. P. Ketineni and T. Ertekin, "Analysis of production decline characteristics of a multistage hydraulically fractured horizontal well in a naturally fractured reservoir," in Proceedings of the SPE Eastern Regional Meeting, Society of Petroleum Engineers, Lexington, Ky, USA, October 2012.

[14] Y.-L. Zhao, L.-H. Zhang, J.-X. Luo, and B.-N. Zhang, "Performance of fractured horizontal well with stimulated reservoir volume in unconventional gas reservoir," Journal of Hydrology, vol. 512, pp. 447-456, 2014.

[15] O. Ozcan, H. Sarak, E. Ozkan, and R. Raghavan, "A trilinear flow model for a fractured horizontal well in a fractal unconventional reservoir," in Proceedings of the SPE Annual Technical Conference and Exhibition (ATCE '14), SPE-170971-MS, pp. 5180-5198, October 2014.

[16] H.-T. Wang, "Performance of multiple fractured horizontal wells in shale gas reservoirs with consideration of multiple mechanisms," Journal of Hydrology, vol. 510, pp. 299-312, 2014.

[17] V. Sesetty and A. Ghassemi, "A numerical study of sequential and simultaneous hydraulic fracturing in single and multilateral horizontal wells," Journal of Petroleum Science and Engineering, vol. 132, pp. 65-76, 2015.

[18] J. Warren and P. Root, "The behavior of naturally fractured reservoirs," SPE Journal, vol. 3, no. 3, pp. 245-255, 2013.

[19] A. A. Daneshy, "Off-balance growth: a new concept in hydraulic fracturing," Journal of Petroleum Technology, vol. 55, no. 4, pp. 78-85, 2003.

[20] E. Ozkan and R. Raghavan, "New solutions for well-testanalysis problems. Part 2. Computational considerations and applications," SPE Formation Evaluation, vol. 6, no. 3, pp. 369378, 1991.

[21] M. F. Riley, "Analytical solutions for elliptical finite-conductivity fractures," in Proceedings of the 66th Annual Technical Conference and E14, Paper SPE 22656, pp. 31-36, Dallas, Tex, USA, 1991.

[22] L. Chu, P. Ye., I. S. Harmawan, L. Du, and L. R. Shepard, Characterizing and Simulating The Nonstationariness and Nonlinearity in Unconventional Oil Reservoirs: Bakken Application/SPE Canadian Unconventional Resources Conference, Society of Petroleum Engineers, 2012. 

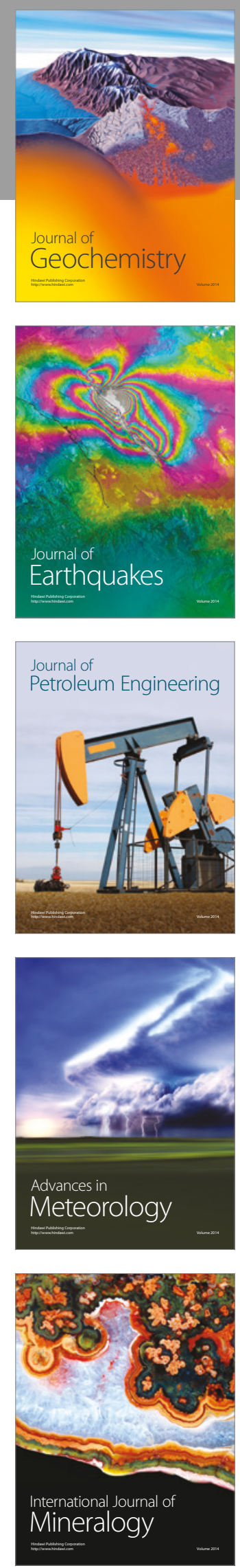
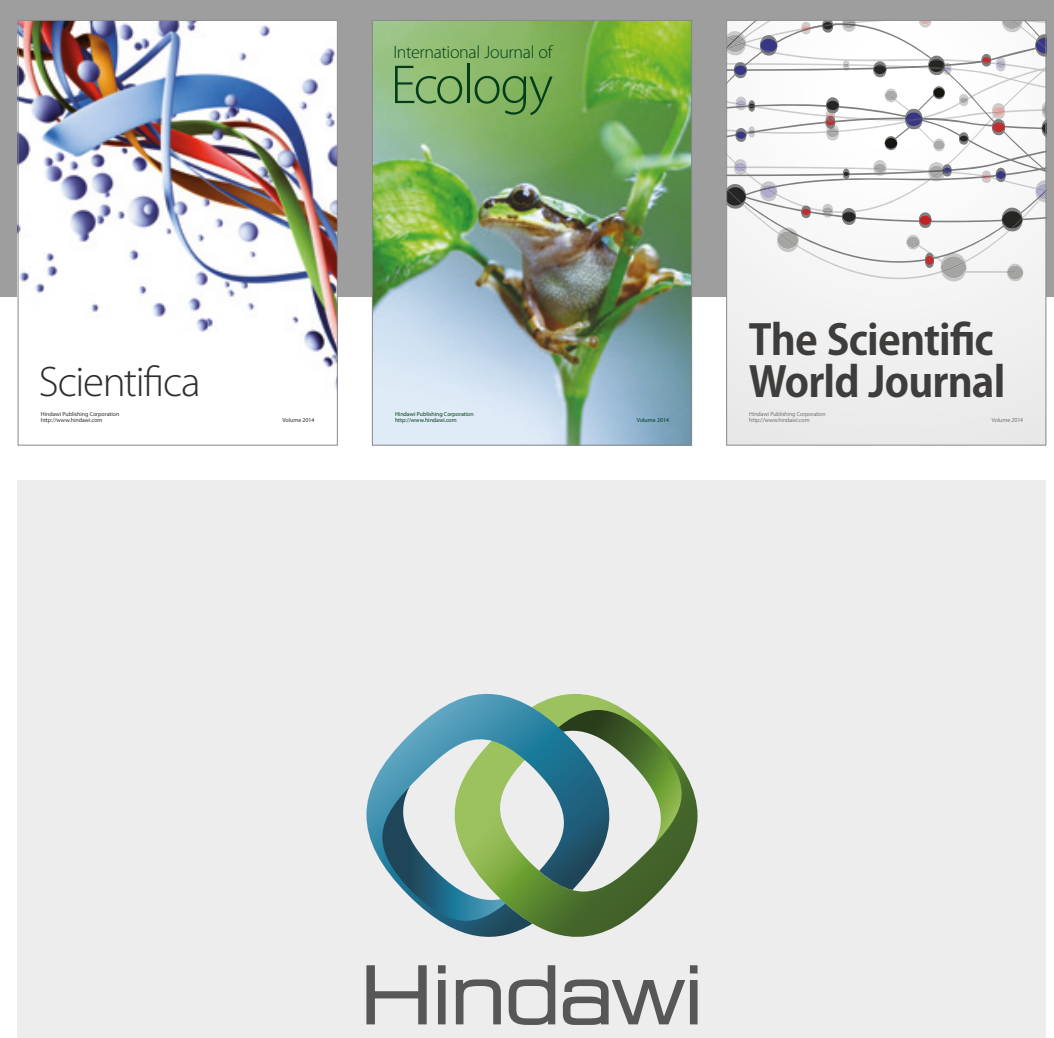

Submit your manuscripts at

https://www.hindawi.com
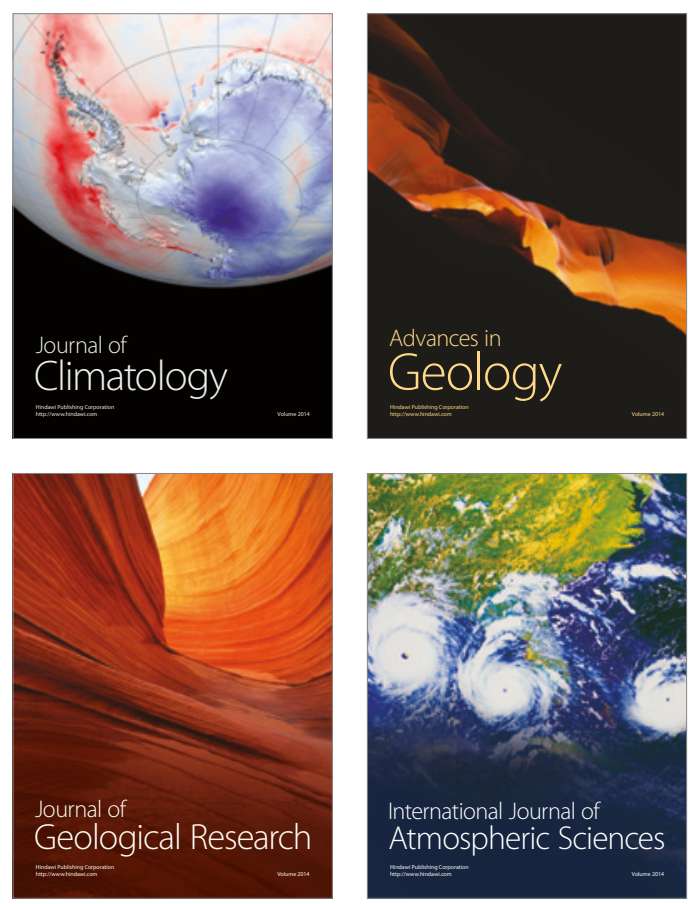

The Scientific

World Journal
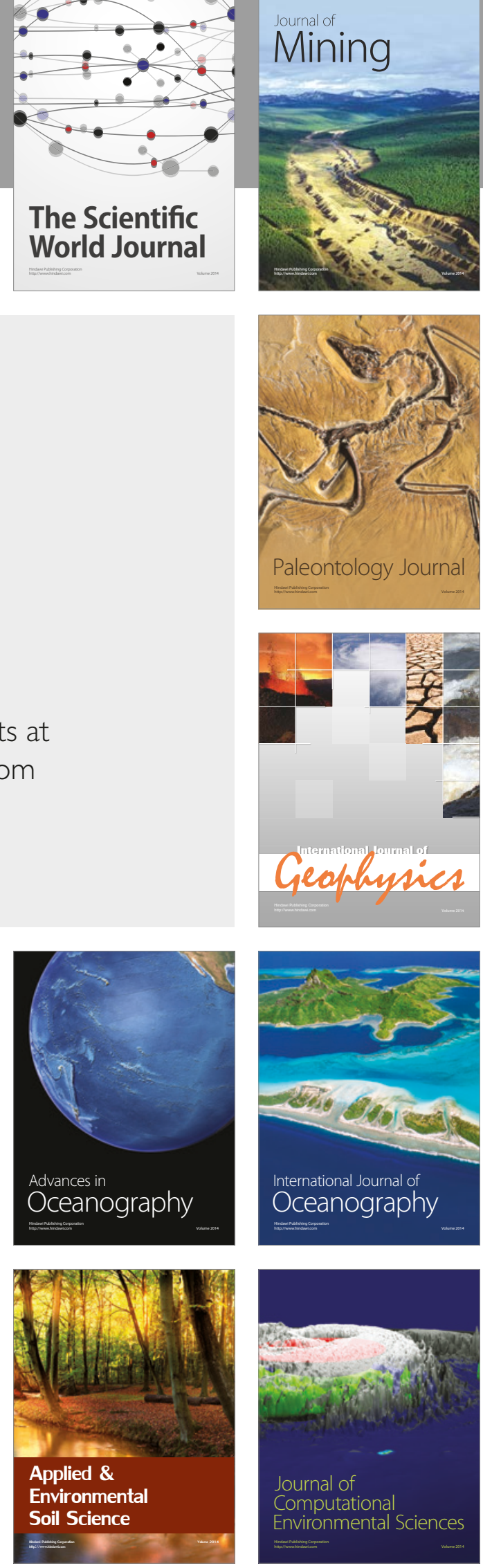